\title{
Analyzing a Human and Environment Unit at The 5th Grade Science Curriculum Within The Environmentally Literate Citizenship Context
}

\author{
Mehmet C. Ayara, Dilek Özalp ${ }^{b}$
}

\begin{abstract}
All the countries have an effort in cultivating environmentally literate citizens since the governments and citizens are responsible to protect the environment. Turkey is one of these countries which integrated environmental education topics and objectives into the science curriculum. Different frameworks have been developed to assess individuals' views about, attitudes and behaviors towards the environment and address environmental issues. These frameworks mostly focus on environmental literacy, but they do not emphasize environmental citizenship. Assessment of the curriculum through the lens of a framework that grounds on both environmental literacy and citizenship is important and needed in order to cultivate environmentally literate citizens. Therefore, this study aimed to investigate the extent to which the newly developed science curriculum provided the opportunity to constitute environmental literate citizenship at the 5th grade level. We benefited a coherent framework grounded by environmental literacy and environmental citizenship in our inquiry to analyze the curriculum. Included among the data collection sources were curriculum documents, objectives, and learning and assessment activities at the 5th grade level. The data analysis consisted of two steps: (i) analysis of the objectives and (ii) content analysis of the human and environment unit at the 5th grade science textbook within the context of environmental literate citizenship. Our findings indicated that the objectives under environmental citizenship required social action and these objectives were associated with critical environmental literacy. In conclusion, the content had the potentiality to help students develop critical viewpoints about environmental issues from critical environmental literacy and justiceoriented citizenship aspects and take social action to make a change in their environment.
\end{abstract}

Keywords: Science Curriculum, Science Textbook, Content Analysis, Environmental Literacy, Environmental Citizenship

\section{Introduction}

Cultivating environmentally literate citizens has been a prominent goal for educators, policymakers, and governments (Green et al., 2016; National Science Teacher Association [NSTA], 2003; Salmon, 2000) because we are facing several problems resulting from human interactions with the environment in a global village such as deforestation, production of waste and pollutants, and overuse of natural resources. Data on water scarcity and drought in Turkey for 2000 and beyond show that there is an increase in water-stressed regions every ten years. In addition, water scarcity in Turkey, especially in metropolitans, is expected to reach its highest level in 2030 (Turan \& Bayraktar, 2020). The National Meteorological Service [NMS] reemphasizes and draws our attention to this problem with the yearly

\section{About the Article}

Type: Research

Received: 11 December 2020

Accepted: 01 March 2021

Published: 30 June 2021

DOI: 10.31805 /acjes.839228

Corresponding Author:

Mehmet C. AYAR

E-mail: mhmtayartx@gmail.com

a Mehmet C. AYAR

ORCID: https://orcid.org/0000-0002-0842-9288

E-mail: mhmtayartx@gmail.com

${ }^{b}$ Dilek ÖZALP

ORCID: https://orcid.org/0000-0002-7817-4866

E-mail: dilekozalp@aydin.edu.tr

\section{Suggested APA Citation}

Ayar, M. C., \& Özalp, D. (2021). Analyzing a human and environment unit at the 5th grade science curriculum within the environmentally literate citizenship context Academy Journal of Educational Sciences, 5(1), 1-14. http://dx.doi. org/10.31805/acjes.839228 
rainfall data collected in the last few decades (NMS, 2017). Besides, in the last five years, people worried that they did not observe snowfall and envision that the next summers would be more challenging, which in turn increase food prices and put the society under stress due to the drought. While these things appear in the media and scientific journals, we wonder how young individuals and communities will react to this problem. Meantime, we question what opportunities the newly developed science curriculum provides for them to take actions and respond to similar problems personally and collectively.

We know that Turkey is one of the countries in the world that enacted a law for environmental education in 1982 (Republic of Turkey Constitution, 1982). According to this act, each citizen has the right to live in a clean, healthy, and stable environment. The government and citizens are responsible for maintaining, restoring, and improving the environment, and preventing environmental problems. This act also encourages each citizen and the government to participate in activities that serve the environment (Ministry of Environment and Forestry [MoEF], 2004). In a line with this act, there have been several attempts in both national and international contexts (e.g., Supreme Council for Science and Technology, the National Science, Technology, and Innovation Strategy (2003-2023) (The Scientific and Technological Research Council of Turkey, 2004), United Nation's Biodiversity Agreement (1997), United Nation's Climate Change Agreement (2004), National Environment Action Plan (1998), National Forestry Program (2004), National Environment Strategy Plan (2006) (Ministry of Environment and Urbanization [MoEU],2011), Climate Change Action Plan (2011-2023) (MoEU, 2011), the Paris Agreement (United Nations Framework Conventions on Climate Change, 2016), and Islamic Declaration on Global Climate Change (The Islamic Foundation for Ecology and Environmental Sciences [IFEES], 2015).

The goal of environmental education is to develop citizens with knowledge, attitudes, and skills necessary for longterm responsible behaviors, and the observable and recordable actions (Green et al., 2016; Roth, 1992; Short, 2010; Stable, 1998). The objectives of environmental education focus on awareness, concern for environment, knowledge, and skills (Chawla \& Cushing, 2007; Rogayan, \& Nebrida, 2019). Environmental literacy refers to knowledge and understanding of a wide range of environmental concepts, problems, and issues, cognitive skills and abilities, appropriate behavioral strategies, and applying knowledge and understanding to make sound and effective decisions (Hollweg et al., 2011).

In an educational context, developing environmental literacy through school curricula is one way of addressing environmental issues in world education systems (Barraza, 2001; Craig \& Allen, 2015; Erdogan et al., 2009; Innes et al., 2018; Gillian \& Niranjan, 2019; Klakayan \& Singseewo, 2016; Lee, 2000; Negev et al., 2008; Ross, 2007; Srbinovski et al., 2010; Sontay et al., 2015; Yucel-Ozata \& Ozkan, 2014). Analyzing environmental literacy and citizenship in educational programs, curricula and textbooks have been a critical issue across many countries (Acuna, 2015; Carvalho et al., 2011; Cheng \& So, 2015; Hart, 2002; Lieflander et al., 2015; Srbinovski, 2013). Specifically, in the Turkish education system, we witnessed three curriculum development efforts (the Year 2005, 2013, and 2017) through which to emphasize environmental education in science curricula for students aged 9-14 in the last two decades. In 2005's science curriculum, the environment component was integrated into thescience-technology-society [STS] framework (Aikenhead,
1992). The students were expected to conceptualize the relationship between science, technology, society, and environment, be sensitive towards environmental issues, and make decisions to serve the environment within the context of recycling, water pollution, deforestation, and environment protection (Ministry of National Education [MoNE], 2005) as the curriculum aimed to cultivate scientifically literate individuals (National Research Council, 1996, 2013; National Science Teacher Association, 2003). Likewise, the Year 2013's science curriculum continued to integrate the environment component into the STS framework. Within the STS-Environment framework, socio-scientific issues (SSI), nature of science, science and technology relationships, and sustainable growth were among the learning areas in the science curriculum. The students were exposed to environmental concepts and issues to generate solutions to light pollution, explain the effects of noise pollution on human health and environment, and propose projects to maintain, restore, and improve the environment (MoNE, 2013). Although the frameworks which were developed to assess individuals' views, attitudes and behaviors towards the environment emphasize environmental literacy, they do not focus on environmental citizenship. Therefore, in this paper, we created a coherent framework ground on both environmental literacy and citizenship, and we aimed to use this framework to investigate the extent to which the newly developed science curriculum provided the opportunity to constitute environmental literate citizenship at the 5 th grade level.

\section{Theoretical Framework}

Many frameworks have been developed to assess individuals' views about attitudes and behaviors towards the environment and address environmental issues (Berkowitz et al., 2005; Erdogan et al., 2009; Hollweg et al., 2011; Kim, 2003; Roth, 1992; Stables, 1998). In this study, we utilize a framework grounded on literacy and citizenship. We benefit from the environmental literacy framework developed by Stables (1998), which focuses on environmental knowledge, cultural perspectives on the environment, and effective action that may generate a solution to environmental problems. In our framework, we associate effective action with citizenship and enlarge it with citizenship adapted to the environmental context. In other words, we broaden critical environmental literacy with citizenship, which comprises three categoriespersonally responsible, participatory, and justice-oriented (Westheimer \& Kahne, 2004) within the environmental context. Therefore, we create a coherent framework to analyze the 5 th grade science curriculum (Figure 1).

\section{Environmental Literacy}

Environmental literacy has been defined within the context of knowledge, skills, behaviors, and attitudes to understand environmental issues from social, political, economic, and cultural perspectives (Hollweg et al., 2011; Kim 2003; McBeth \& Volk 2009; OECD, 2016; Roth, 1992). Stables (1998) categorized environmental literacy into three: (1) functional environmental literacy, (2) cultural environmental literacy, and (3) critical environmental literacy. Functional environmental literacy is a prerequisite for cultural and critical environmental literacy. It is associated with the ability to recognize the interactions between humans and the environment to develop a broader knowledge and understanding. Yet, it does not engage an individual with a notion of what environment means to her and others. Cultural environmental literacy requires knowledge and skills to explain the importance of natural things to the culture and their existence in the culture without any human intervention. 
Critical environmental literacy refers to effective action, which needs functional and cultural perspectives to unders by Stables (1998) because its definition and categories are very likely to be close to the Turkish environmental education standards (Erdogan et al., 2009).

\section{Environmental Citizenship}

Citizenship refers to how individuals act in society. For one perspective on citizenship, individuals get accustomed to how the government works and know their responsibilities to the government and society. For the other, they active engagement and civic participation to address those structural causes, acting individually and collectively within democratic means, and taking into account inter- and intra-generational justice.

Environmental citizenship includes having the knowledge and awareness about the environmental issues, feeling responsibility and consciousness toward the environmental problems, having the ability to produce solutions for the problems, and showing respectful behavior to solve those problems (Smederevac-Lalic et al., 2020). Environmental citizenship requires to make a commitment to the common

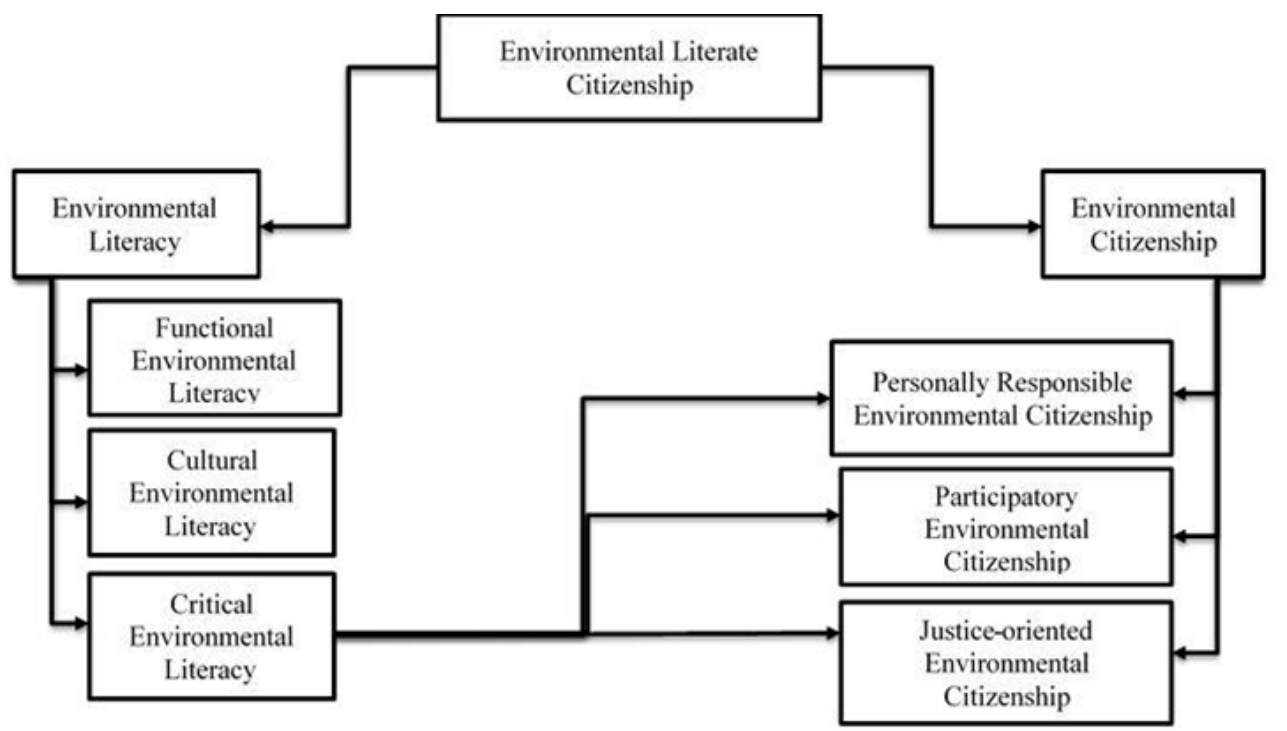

Figure 1. Environmental literate citizenship framework adapted from Stables (1998) and Westheimer and Kahne (2004).

participate in community organizations, solve problems, and pursue a social change in society (Dimick, 2015). Citizenship is grounded on a reaction of individuals to any situation or phenomena as Weber (1978) defined social action. In this regard. Westheimer and Kahne (2004) discussed three categories of citizenship-personally responsible, participatory, and justice-oriented. In an environmental context, a personally responsible citizen can act responsibly in a community and contributes to a recycling bin at home, work, and school. A participatory citizen can be an active member of a community organization and can participate in community organizations to create recycling bins at home, work, and school. Justice-oriented citizens, sharing a similar vision with participatory one, commit to analyzing why people do not recycle, exploring the ways to encourage recycling through public announcement, and reporting the process. The European Network for Environmental Citizenship (2018a) defined environmental citizenship as;

The responsible pro-environmental behavior of citizens who act and participate in society as agents of change in the private and public sphere, on a local, national and global scale, through individual and collective actions, in the direction of solving contemporary environmental problems, preventing the creation of new environmental problems, achieving sustainability as wellas developing a healthy relationship with nature. Environmental citizenship includes the exercise of environmental rights and duties, as well as the identification of the underlying structural causes of environmental degradation and environmental problems, the development of the willingness and the competences for critical and good, to recognize the rights and responsibilities that transcend national boundaries, to know environmental responsibilities followed from environmental rights as a matter of naturaljustice, and to live sustainably so that others may live well (Dobson, 2007). Therefore, environmental citizenship may necessitate individuals' reactions to examine and interpret the interactions between human and environment from a variety of perspectives-physical, geographical, biological, sociological, economic, political, technological, historical, aesthetic, ethical, and spiritual (Kim, 2003; Stable, 1998; Schild, 2016).

Education for environmental citizenship aims to improve environmental knowledge and competences, to develop positive values, beliefs, attitudes toward the environment, and to enable their active participation to solve environmental issues as citizens (Goldman et al., 2020). All the countries have an effort in cultivating environmentally literate citizens since the governments and citizens are responsible to protect the environment. As one way to achieve this goal, they have integrated the environmental education topics into their curricula. To find out whether those efforts have been met, there should be some kind of criteria that include the expectations regarding environmentally literate citizens. Different frameworks have been developed to assess individuals' views about attitudes and behaviors towards the environment and address environmental issues. These frameworks mostly focus on environmental literacy, but they do not emphasize environmental citizenship. Therefore, in this paper, we generated a coherent framework ground on environmental literacy and citizenship to explore to what degree the fifth-grade science curriculum enables students to develop their reactions to environmental problems or issues and to engage with the solutions. 


\section{Methodology}

\section{Research Design}

In this research, the case study which is one of the qualitative research approaches was used since we found that it is the most appropriate one in giving in-depth exploration of the situation that we examined. Case-study research involves the study of a situation explored through one or more cases, giving in-depth exploration of the particularity and complexity of the studied case or cases (Creswell, 2007). The data for this study were collected through curriculum documents, objectives, and textbook in order to provide a full understanding of the situation and explore the extent to which the newly developed science curriculum provided the opportunity to constitute environmental literate citizenship at the 5 th grade level.

\section{Data Collection}

In this study, we used qualitative documents as the data collection procedure. The qualitative documents can be public documents such as the official reports or they can be private documents such as diaries, (Creswell, 2014). In this research, we analyzed the newly developed science curriculum within the environmental literate citizenship context through several data sources such as curriculum documents, objectives, and learning and assessment activities at the 5 th grade level science textbook.

\section{Data Analysis}

Our data analysis consisted of two steps: (i) analysis of the objectives and (ii) content analysis of the human and environment unit at the 5th grade science textbook within the context of environmental literate citizenship. In this research, we developed an environmental literate citizenship framework which includes separate criteria for environmental literacy and environmental citizenship. For the data analysis of this study, first, we focused on the fifthgrade objectives from the list throughout the curriculum to determine their relevance to environmental education. Then we utilized the environmental literate citizenship framework to evaluate the objectives. Environmental literacy component had three categories-functional environmental literacy (F), cultural environmental literacy (C), critical environmental literacy (Cr) (Stables, 1998), and environmental citizenship component had three categories- personally responsible, $(\mathrm{P})$ participatory $(\mathrm{Pa})$, and justice-oriented $(\mathrm{J})$ (Westheimer \& Kahne, 2004). We generated expressions referring to each category within environmental literacy and environmental citizenship. We conceived of each expression as an evaluation criterion for curriculum objectives. We listed five criteria under functional environmental literacy category, seven criteria under cultural environmental literacy category, and nine criteria under critical environmental literacy category; five criteria under personally responsible citizen category, six criteria under participatory citizen category, and five criteria under justice-oriented citizen category (Stables, 1998; Westheimer \& Kahne, 2004).

Two researchers, one is curriculum development specialist, and the other is science education expert, independently analyzed each objective in the curriculum and matched the objective with the criteria within the context of environmental literacy (Appendix A). For instance, the objective -explains the destructive natural disasters caused by the natural processes [F.5.1.5.1] was located under the first criterion in $\mathrm{F}$ (providing of saying or remembering what is meant by a concept regarding environment). Another objective - provides suggestions for resolving an environmental problem in the immediate surrounding or in our country [F.5.6.2.2] was located under the second criterion in $\mathrm{Cr}$ (provides forming a view on how to further oppose the environmental problems in a way that can be later translated to action). Then we gathered to decide how much we agreed on the categorization of objectives from environmental literacy aspects. We met disagreements on the categorization of some objectives. We calculated the coefficient of consistency as 0.94 (Krippendorff, 2018). We removed some objectives from the objective list because they were not relevant to environmental education. For instance, one objective was about the negative effects of cigarettes and alcohol on human health, the other was concerning the carbon monoxide intoxication and its precautions. We also utilized environmental citizenship categories to analyze the objectives (Westheimer \& Kahne, 2004). For our analysis, we individually matched the objectives with the criteria of the categories within the environmental citizenship context (Appendix B). For instance, the objective -questions the importance of biodiversity for natural life giving examples to plants and animals that are endangered or facing danger of extinction in our country and in the world [F.5.6.1.1] was located under the first criterion in $\mathrm{J}$ (critically assesses the problems or issues related to the environment and evaluates in terms of social, cultural, economic and political aspects). And the objective - makes inferences about the environmental problems that may arise in the future as a result of human activities [F.5.6.2.3] was located under the fourth criterion in J (analyzes the insensitivity and behaviors of people and society to solve environmental problems). We had some disagreements on several objectives. For instance, while one researcher included five objectives into the categories, the other did not make any decision or missed the objectives in the list. In addition, we came to agree on one objective concerning participation in environmental cleaning in the home, school, and class that would be personally responsible citizen category rather than the participatory citizen category. It is because the objective did not require a citizen to organize a cleaning activity. Rather, the objective asked them to act responsibly in their environment. Therefore, we reached a consensus on the categorization of the objectives regarding environmental citizenship and the coefficient of consistency was calculated as 0.97 (Krippendorff, 2018).

Second, we examined the 5th grade science curriculum because at the time only 5th grade objectives and its science textbook had been released by the government across the country. Thus, we performed the content analysis of two chapters under the human and environment unit at the 5 th grade science textbook according to the criteria for environmental literacy and citizenship (Appendix-A and B). Two chapters were associated with natural disasters and biodiversity, and human-environment relationship topics. For the content analysis, we independently analyzed each chapter line by line to understand the extent to which the content of these topics represented environmental literate citizenship. For instance, we worked on two objectives such as (1) Students will be able to explain destructive natural phenomena led by natural processes and (2) Students will be able to express the ways to protect from destructive natural phenomena. In this sense, we searched for the statements from the chapters that would be possibly associated with the categories of environmental literacy and environmental citizenship. For instance, we found a statement, "Soil pollution decreases biodiversity by destroying the living spaces of living things" and associated it with functional environmental literacy because it aimed to enable students 
to know the subject matter. In addition to that, another statement from the textbook, "Fruits and vegetables such as Gherkin, govelez, oleaster, Celtis, ahlat, hunnap, maythorn, alfalfa, vetch, cherry laurel are among our biological riches in the biodiversity of our country [Turkey]," would be associated with cultural environmental literacy because it aimed to make students understand the importance of natural images in their culture. Somewhere in the text, we met some precautions against environmental pollution. For example, one precaution listed there was about recycling. It said, "Wastes of paper, plastics, battery, and glass should be thrown into recycling bins." Because this precaution aimed to enable individuals to act as responsible for recycling, we decided that this would be associated with the personally responsible citizen category. We met some questions in the text as we read the chapter such as, "What might be the reasons for the extinction of the living beings in our country?" We associated this question with the justice-oriented citizen category because it targeted to enable students to critically assess the problem of extinction of some species that could be related to the environment and evaluate the extinction in terms of social, cultural, economic, and political aspects. Although we had disagreements on claims, statements, and questions at the textbook, which would be associated with environmental literacy and environmental citizenship, we calculated the coefficient of consistency as 0.95 (Krippendorff, 2018).

\section{Findings}

\section{Analysis of Objectives within the Environmental Literacy Context}

At the 5th grade level, we observed that eight out of thirtysix objectives were relevant to environmental education (Appendix A). Our findings indicated that only three objectives were under the functional environmental literacy category. These objectives were associated with a criterion referring to remembering and telling a concept of the environment (F1). It was because the first objective was to explain the destructive natural disasters caused by the natural processes, the second does so to explain the importance of interaction between humans and the environment and the third expresses the ways of protection from the destructive natural disasters. We located five objectives under the critical environmental literacy category. Specifically, the first objective, referring to discussing the factors that threatens biodiversity based on research data was matched with Cr1(providing the understanding of the factors that cause environmental change/problems). Second-providing suggestions for resolving an environmental problem in the immediate surrounding or our country - and third expressing the ways of protection from the destructive natural disasters were located under $\mathrm{Cr} 2$ (initiatives to take action on environmental issues and problems). Fourthquestioning the importance of biodiversity for natural life... giving examples to plants and animals that are endangered or facing the danger of extinction in our country and the world-was located under $\mathrm{Cr} 3$ (questioning of what a place or an environmental problem means for itself). Finally, we matched $\mathrm{Cr} 5$ (referring to how to respond to environmental problems to generate a solution) with two objectivesmaking inferences about the environmental problems that may arise in the future as a result of human activities and discussing the examples of cons and pros of the relationship between human and environment. Based on the findings, we can say that at the 5 th grade level the objectives encourage the students more to remember and tell a concept of the environment, understand causes-effects on environmental change, and generate a solution to respond to that change. on the other hand, the objectives do not primarily focus on the knowledge and skills to explain the importance of natural things to the culture and their existence in the culture without any human intervention.

\section{Analysis of Objectives within the Environmental Citizenship} Context

At the 5th grade level, there were no objectives associated with personally responsible and participant environmental citizenship. Yet, there were five objectives at the 5th grade level relevant to the justice-oriented environmental citizenship (J) (Appendix B). We matched one objective referring to questioning the importance of biodiversity for natural life and another objective referring to discussing the factors that threaten biodiversity based on research data with the J1. Two objectives-making inferences about the environmental problems that may arise in the future because of human activities and discussing the benefits and harmful situations in human-environment interaction on examples- were under the J4 respectively. Only one objective that was to provide suggestions for resolving an environmental problem in the immediate surrounding or our country was under the J5. Overall, it can be said that at the 5 th grade level the objectives more focus on critically assessing the environmental problems in terms of social, cultural, economic and political aspects, analyzing the behaviors of people and society to solve those problems, questioning environmental issues for environmental justice, and trying to change the built-in system.

\section{Content Analysis within Environmental Literacy Context}

We identified a human and environment unit including two chapters associated with environmental education at the 5th grade textbook. The first chapter focused on natural disasters, biodiversity, natural life, extinct species, and species under risk of extinction topics. The second included environmental pollution, greenhouse effect, global climate change, and environmental protection and landscaping topic under the human-environment relationship. Here, we presented and explained some examples associated with three categories of environmental literacy. In the text, we realized that some factors threatening biodiversity in Turkey and the world were listed such as overpopulation, environmental pollution, overhunting, global warming, erosion, natural disasters, and overgrazing. In addition to this, somewhere in the textbook, we captured several statements, such as soil pollution decreases biodiversity by destroying the living species of living things. To put in detail, chemical substances used in farming accumulate on plants. These plants harm human health when consumed by people and the climatic conditions, the terrestrial forms of the earth structure, the earthquakes, and the relationship between living things that affect the biodiversity of the region [Excerpt 8]. Since the number and variety of living things in a region is called biodiversity, the climatic conditions, the terrestrial forms of the earth structure, the earthquakes, and the relationship between the living things affect the biodiversity of the region [Excerpt 9]. These statements were associated with the objective-explaining the importance of interaction between humans and the environment [F.5.6.2.1]. That is, they were the representation of functional environmental literacy. It was because these statements indicated the concept of biodiversity regarding the environment and the negative effects of environmental pollution on health. Also, we found two more statements, a flood is a condition in which the soil that is in a particular area is completely, or partially underground [Excerpt 11] associated with the objectiveexplaining the destructive natural disasters caused by the natural processes [F.5.1.5.1] and residential areas should not be located where landslides are likely. The natural vegetation 
must be preserved in the sloped terrain. Water channels should be opened throughout the slope to allow the water to run easily and not cause any landslides [Excerpt 4] associated with the objective-expressing the ways of protection from the destructive natural disasters [F.5.1.5.2]. These statements represented the destructive natural disasters and ways of protection from them. All referred to as a criterion of functional environmental literacy-remembering and telling a concept of the environment [F1] (Table 1).

In the biodiversity unit, the textbook provided some information about a natural trip to the Mediterranean. The excerpt we captured from the textbook was below:

Melisa observed Laurus nobilis [laurel], arbutus, Myrtus communis [myrtle], qercus aucheri [a kind of oak], and olea [olive tree] during the trip. As they passed through Mount Ida (Kazdagi), Melisa saw eagle and hawk floating through the sky. Her father told her they were predators and endemic to the region. [Excerpt 1]

This excerpt represented the critical environmental literacy in a way that introduced questioning of what a place or an environmental problem means for itself. Another excerpt continued to mention fruits and vegetables such as gherkin, govelez; oleaster, Celtis, ahlat, hunnap, maythorn, alfalfa, vetch, and cherry laurel are among our biological riches in the biodiversity of our country [Turkey] [Excerpt 2]. These excerpts were the representation of the first part of the objective in the text-...questioning the importance of biodiversity for natural life as referring to a criterion of questioning of what a place or an environmental problem means for itself. [Cr3]. Yet, it did not represent the second part of the objective-giving examples to plants and animals that are endangered or facing the danger of extinction in our country and the world. [F.5.6.1.1] (Table 1).

Furthermore, our content analysis comprised of miniactivities provided in the textbook. One activity was about investigating a picture of nature demonstrating a chain of mountains, rivers, and forests. Possibly this picture would be called a natural wonder. However, the text informed students, this natural wonder will be transformed into residential areas. With its greenness, blueness, and biological diversity, it has been planned to construct buildings, parks, and factories in the area of the natural wonder. With the opening of these factories in this area, there will be many job opportunities for people [Excerpt 6]. We associated this excerpt with the objective-making inferences about the environmental problems that may arise in the future as a result of human activities [F.5.6.2.3] (Table 1). Based on this information, students were asked, when construction was completed in this area, what kind of environmental issues would people face? What could be the positive and negative consequences of building factories and residential areas in this place? [Excerpt 7]. We associated this excerpt with the objectivediscussing the benefits and harmful situations in humanenvironment interaction on examples [F.5.6.2.4] (Table 1). Then, they were expected to write their assumptions. We put this activity under the critical environmental literacy category because students were expected to analyze the factors that would threaten biodiversity and cause environmental problems or changes [Cr5].

In another activity, Tom and his friends were expected to investigate water pollution in a river. To do so, they listed a variety of plants and animals in certain remote areas around the river. They began to search the river about $3 \mathrm{~km}$ away from the part of the bog. Then, they presented their results after their research. They found that there were 60 water plants, 5 ducks, 25 frogs, and 45 water bugs in the park near the river about $3 \mathrm{~km}$ away from the bog. They also added that there were 40 water plants, 1 duck, 12 frogs, and 20 water bugs on the roadside about $2 \mathrm{~km}$ away from the bog. Their results also included the area nearby a painting factory about $1 \mathrm{~km}$ away from the bog. They observed 15 water plants, zero duck, 1 frog, and 5 water bugs in this area. Finally, they listed that there were 80 water plants, 5 ducks, 4 frogs, and 52 water bugs in the area of the bog. Using this information, students were expected to answer some questions, such as why do you think that bog resulting from pollution has more species and is rich in biodiversity? Which would be the least polluted area? What are the reasons for the decrease in the number of frogs and ducks on the roadside? [Excerpt 3]. This activity was associated with the objective-discussing the factors that threaten biodiversity based on research data. [F.5.6.1.2] (Table 1). It represented the critical environmental literacy because students were expected to examine and compare the results given in the table. Moreover, they would consider and question what might be the consequences of such environmental problems [Cr1] (Table 1).

Besides, we met a statement-identify an environmental problem at your local residence. Write down the precautions you need to take to eliminate the environmental problem you have identified [Excerpt 5]. We associated this excerpt with the critical environmental literacy expression such as, provides forming a view on how to further oppose the environmental problems in a way that can be later translated to action [Cr2]. This statement also referred to as the objective-providing suggestions for resolving an environmental problem in the immediate surrounding or our country [F.5.6.2.2]. It is because the students were expected to generate solutions to a problem in an environmental context, which in turn would lead to taking action (Table 1).

Overall, we can say that the 5th grade textbook encourages the students more to remember and tell a concept of the environment, understand causes-effects on environmental change, and generate a solution to respond to that change. On the other hand, the textbook does not primarily focus on the knowledge and skills to explain the importance of natural things to the culture and their existence in the culture without any human intervention.

\section{Content Analysis within Environmental Citizenship Context}

Some excerpts we used for content analysis within the critical environmental literacy context occurred in this step. Here, we listed some excerpts from the 5th textbook in Table 2. As we mentioned above about Melisa's trip with her family to Mount Ida and during her trip, she met plant and animal species endemic to the area she has passed through. We focused on the same excerpt because there was a question at the end-why is biodiversity important for a country [Turkey]? [Excerpt 14] We envisioned that the question given aimed to help students question the importance of biodiversity. That question would spark their interest in understanding such as; the loss of biodiversity affects the extinction of some plants and animals in advance [F.5.6.1.1]. In addition, there were additional questions in the text such as, what animals do you see when you look around? What could be the importance of having so much diversity of living things in nature? [Excerpt 13] Therefore, we concluded that the statements and questions from the story had the potential to enable students to critically assess environmental problems and make evaluations in terms of social, cultural, economic, and political aspects [J1] (Table 2). 
Table 1. Excerpt for the content analysis of the textbook within environmental literacy context.

\begin{tabular}{|c|c|c|c|}
\hline Category & Criteria & & \\
\hline \multirow{6}{*}{ 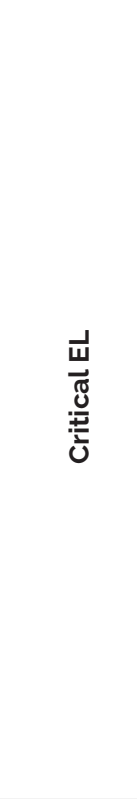 } & $\mathrm{Cr} 1$ & F.5.6.1.2. & $\begin{array}{l}\text { Tom and his friends have searched and listed the variety of plants and animals living in certain } \\
\text { remote areas around the river to search for pollution in a river. They started to search the river } \\
\text { about } 3 \mathrm{~km} \text { away from the part of the bog... Why do you think that bog resulting from pollution has } \\
\text { more species and is a rich of biodiversity? Which would be the least polluted area? [Excerpt 3] }\end{array}$ \\
\hline & $\mathrm{Cr} 2$ & F.5.6.2.2 & $\begin{array}{l}\text { Identify an environmental problem at your local residence. Write down the precautions you need } \\
\text { to take to eliminate the environmental problem you have identified. [Excerpt 5] }\end{array}$ \\
\hline & $\mathrm{Cr}_{3}$ & F.5.6.1.1. & $\begin{array}{l}\text { Elf observed laurus nobilis [laurel], arbutus, myrtus communis [myrtle], qercus aucheri la kind of } \\
\text { oak], and olea lolive tree] during the trip. As they passed through the Mount Ida (Kazdagi), Elf saw } \\
\text { eagle and hawk floating through the sky. Her father told her they were predators and epidemic to } \\
\text { the region. [Excerpt 1] }\end{array}$ \\
\hline & & & $\begin{array}{l}\text { Fruits and vegetables such as gherkin, govelez, oleaster, celtis, ahlat, hunnap, maythorn, alfalfa, } \\
\text { vetch, cherry laurel are among our biological riches in the biodiversity of our country. [Excerpt 2] }\end{array}$ \\
\hline & $\mathrm{Cr} 5$ & F.5.6.2.3 & $\begin{array}{l}\text {.... it has been planned to build buildings, parks and factories in this area. With the opening of } \\
\text { these factories, there will be many job opportunities for people. When construction was complete } \\
\text { in this area, what kind of environmental issues people would face? What could be the positive } \\
\text { and negative consequences of building factories and residential areas in this place? Write your } \\
\text { assumptions. [Excerpt 6] }\end{array}$ \\
\hline & & F.5.6.2.4 & $\begin{array}{l}\text { What could be the positive and negative consequences of building factories and residential areas } \\
\text { in this place? [Excerpt 7] }\end{array}$ \\
\hline \multirow{4}{*}{ 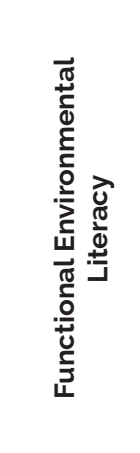 } & $F_{1}$ & F.5.6.2.1. & $\begin{array}{l}\text { Soil pollution decreases biodiversity by destroying the living spaces of living things. Chemical } \\
\text { substances used in farming accumulate on plants. These plants harm human health when } \\
\text { consumed by people. [Excerpt 8] }\end{array}$ \\
\hline & & & $\begin{array}{l}\text { The number and variety of living things in a region is called as biodiversity. The climatic } \\
\text { conditions, the terrestrial forms of the earth structure, the earthquakes, and the relationship } \\
\text { between the living things affect the biodiversity of the region. [Excerpt } 9 \text { ] }\end{array}$ \\
\hline & & F. 5.1.5.1 & $\begin{array}{l}\text { Flood is a condition in which the soil that is in a particular area is completely, or partially } \\
\text { underground. [Excerpt 11] }\end{array}$ \\
\hline & & F.5.1.5.2. & $\begin{array}{l}\text { Residential areas should not be located where landslides are likely. The natural vegetation must } \\
\text { be preserved in the sloped terrain. Water channels should be opened throughout the slope to } \\
\text { allow the water to run easily and not cause any landslides. [Excerpt 4] }\end{array}$ \\
\hline
\end{tabular}

Table 2. Excerpt for the content analysis of the textbook within environmental citizenship context

\begin{tabular}{|c|c|c|c|}
\hline Category & Criteria & & \\
\hline \multirow{8}{*}{ 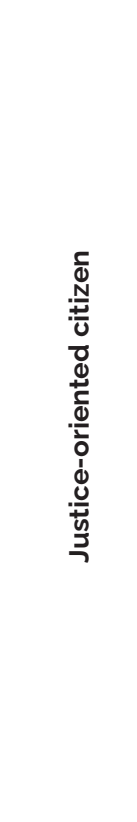 } & \multirow{5}{*}{\multicolumn{2}{|c|}{$F[611$}} & $\begin{array}{l}\text { What animations do you see when you look around you? What could be the importance for us } \\
\text { having so much diversity of living things in nature? [Excerpt 13] }\end{array}$ \\
\hline & & & $\begin{array}{l}\text {...Along the road, sweetbay, oak and wild olive trees were like friends with them. As they passed } \\
\text { through the Mount Ida (Kazdagi), the Elf saw the eagle and hawk in the sky... Why is biodiversity } \\
\text { important for a country? Please Explain. [Excerpt 14] }\end{array}$ \\
\hline & & & What might be the reasons for the extinction of the living beings in our country? [Excerpt 15] \\
\hline & & & $\begin{array}{l}\text { Tom and his friends have searched and listed the variety of plants and animals living in certain } \\
\text { remote areas around the river...What could be the reason for the decrease in the number of frog } \\
\text { and ducks on the roadside? [Excerpt 16] }\end{array}$ \\
\hline & & & $\begin{array}{l}\text {... most of the fruits and vegetables grow up early and rotted on their branches. There is something } \\
\text { weird this year. The seasons came } 20 \text { days-1 month earlier... What is the reason of the situation in } \\
\text { the passage? [Excerpt 17] }\end{array}$ \\
\hline & \multirow[t]{2}{*}{$\mathrm{J}_{4}$} & F.5.6.2.3 & $\begin{array}{l}\text {... it is planned to build buildings, parks, and factories in this area. With the opening of these } \\
\text { factories, there will be many job opportunities for people. What kind of environmental problems } \\
\text { may arise when the construction is completed? [Excerpt 18] }\end{array}$ \\
\hline & & F.5.6.2.4 & $\begin{array}{l}\text {... What could be the positive and negative consequences of building factories and residential } \\
\text { areas in this place? Write your estimations. [Excerpt 19] }\end{array}$ \\
\hline & J5 & F.5.6.2.2. & $\begin{array}{l}\text { Identify an environmental problem at your local residence. Write down the precautions you need } \\
\text { to eliminate the environmental problem you have identified. [Excerpt 20] }\end{array}$ \\
\hline
\end{tabular}


For the same criterion, J1, with a different objective [F.5.6.1.2], we found some statements. For instance, there was a question like, what might be the reasons for the extinction of the living beings in our country? Also, there was a passage, "...most of the fruits and vegetables grow up early and rotted on their branches. There is something weird this year. The seasons came twenty days-1 months earlier... What is the reason for the situation in this case?" [Excerpt 17]. Moreover, we used the activity in which Tom and his friends investigated water pollution in a river with research data [Excerpt 3, 16]. This time we focused on the same activity concerning the justice-oriented citizenship category because this activity had the potential to make students discuss the factors that would threaten the biodiversity based on research data. In turn, it would enable them to critically assess and evaluate environmental issues from social, cultural, economic, and political perspectives [J1] (Table 2).

We had another activity about the transformation of a natural wonder into a residential area where to build apartments, parks, and factories as stated in Excerpt 18 as ...it is planned to build buildings, parks, and factories in this area. With the opening of these factories, there will be many job opportunities for people. What kind of environmental problems may arise when the construction is completed? This question aimed to enable students to make inferences about the environmental problems that may emerge shortly because of people's intervention on nature [F.5.6.2.3]. Somewhere in the text, several questions were providedwhat kind of environmental problems may arise when the construction is completed? What could be the positive and negative consequences of building factories and residential areas in this place? [Excerpt 19]. These questions were to discuss the benefits and harmful situations of the humanenvironment interactions as referring to the objective [F.5.6.2.4]. These statements also showed that there was a potentiality to analyze behaviors of people when they interacted with the environment and to generate solutions to problems if any [J4] (Table 2).

We captured another statement such as; identify an environmental problem at your local residence. Write down the precautions you need to eliminate such a problem [Excerpt 20]. We associated this statement with the objective referring to providing suggestions to resolve an environmental problem... [F.5.6.2.2.] because identifying an environmental problem around their residence and listing some precautions to such a problem could make students internalize the situations and get motivated to bring the change to their society. Instead of bringing problems irrelevant to their daily life, offering them to identify a problem from their daily life would have them internalize and encourage them to bring environmental justice in society. Therefore, this statement matched with J5 referring to monitoring and questioning environmental issues for environmental justice and tries to change the built-in system (Table 2).

The findings within environmental citizenship context indicate that the 5th grade textbook more focuses on critically assessing the environmental problems in terms of social, cultural, economic and political aspects, analyzing the behaviors of people and society to solve those problems, questioning environmental issues for environmental justice, and trying to change the built-in system.

\section{Discussion and Conclusion}

In our inquiry, many objectives across the whole curriculum represented two components of the environmental literate citizenship framework-environmental literacy and
environmentalcitizenship.Verylimitedobjectivesrepresented environmental literacy. As a result, it can be said that the newly developed curriculum provides more opportunities to constitute environmental citizenship but less opportunities to constitute environmental literacy. Among the schooling goals, it was not expected to cultivate "critical thinkers, social inquirers, and problem solvers, or active participants in environmental and political (or even educational) decision making" (Stevenson 2007, 145). According to Srbinovski et al. (2010), more attention was given to functional environmental literacy in the science curriculum. On one hand, our analysis is a contrast to Stevenson (2007) and Srbinovski et al. (2010) because there was more space for critical environmental literacy compared to the other categories throughout the whole curriculum. This suggests that the new curriculum have more potential to cultivate critical environmental literacy but have less potential to cultivate functional and cultural environmental literacy. On the other, the results from Stevenson (2007) and Srbinovski et al. (2010) supported our analysis because there was more space for functional environmental literacy at the 5th-grade level. In addition, we observed no attention given to the cultural dimension of environmental literacy at the 5th grade level. This was in a line with Acuna (2015) that cultural aspects were limited to understand the interactions between humans and the environment in Chilean school textbooks. At an early age, exposure to environmental education is a means to develop positive attitudes towards the environment and contribute to cognitive development (Horwitz, 1996). Our analysis at the 5 th grade level showed only eight objectives. Out of eight objectives, five were under the critical environmental literacy category in contrast to Srbinovski (2013). The remaining was located under functional environmental literacy. This results that 5 th grade science curriculum provides more opportunities to constitute critical environmental literacy but less opportunities to functional environmental literacy. In addition, it does not have any potential to improve cultural environmental literacy.

Within the environmental citizenship context, there was more space for justice-oriented environmental citizenship at the 5th grade level. In contrast, most educational programs put more focus on personally responsible environmental citizenship (Westheimer \& Kahn, 2004). In more specifically, at the 5th grade level, there were five objectives under justiceoriented citizenship. On the contrary, the Chilean school textbooks provided limited opportunities for individuals to take social action. The textbooks did not encourage collective action towards environmental problems (Acuna, 2015). This suggests, 5th grade science curriculum provides more opportunities to constitute justice-oriented environmental citizenship, but it does not have potential to constitute personally responsible and participatory citizenships.

In our theoretical framework, we associated the categories of environmental citizenship with the critical environmental literacy because environmental citizenship required participation and action in different degrees to understand causes-effects on environmental change and generate a solution to respond to such change. This would be aligned with criticalenvironmental literacy (Stables, 1998). Ouranalysis had evidence that the content of a human and environment unit had the potential to cultivate environmentally literate citizens. This was in line with Chawla and Cushing's (2007) suggestion that educators encourage students to gain knowledge, form positive attitudes about the environment, and practice action skills. Moreover, the objectives associated with two components of the environmental literate citizenship framework appeared throughout the text. In other words, the text was written in light of the objectives 
and highlighted the essence of environmental literate citizenship. Yet, eight objectives represented the functional and critical environmental literacy, whereas five did so the justice-oriented environmental citizenship at the 5th grade science textbook. Five objectives of environmental citizenship were aligned with critical environmental literacy. This was coherent with our theoretical framework. As a result, we can say that 5 th grade science textbook provides more opportunities to constitute critical environmental literacy and justice-oriented citizenship but less opportunities to functional environmental literacy. In addition, it does not have potential to improve cultural environmental literacy, and personally responsible and participatory citizenships. This result is coherent with the 5 th grade curriculum.

First, literacy and citizenship have different definitions in nature. Literacy may not require individuals to act necessarily as in the functional and cultural environmental literacy whereas citizenship empowers individuals to have knowledge, skills, and attitudes to act as in critical environmental literacy (Berkowitz et al., 2005; Ellis \& Waterton, 2004). Likewise, our analysis indicated that the objectives under environmental citizenship required social action, and these objectives were associated with critical environmental literacy. We think that this result occurs normally in the conventional classroom, where the teacher transferred content knowledge to the students and made them familiar with environmental issues. We assumed that due to students' grades and knowledge level, enabling them to take action on environmental issues was missing. In contrast, engaging students with environmental issues and providing opportunities to take action could help them become active learners (Short, 2010). For instance, Hart (2002) stated that science curricula in environmental education should provide the students with experiences. Hart added that those experiences require the instructional leadership that stresses engagement, reflection, and actionoriented group work in natural settings as modes of learning. In addition, Venville et al. (2009) pointed out this problem as referring to several countries where students were highly engaged in high-stakes tests, which in turn reduced their contextual, issue-based, and applied to learn.

Second, among the objectives under environmental literacy, the whole curriculum puts more emphasis on the critical aspects of environmental education quantitatively. In contrast, Cermak (2010) indicated that the textbook and teacher limited the students to gain more functional environmental literacy characteristics and less cultural and critical environmental literacy characteristics. Also, Walker (1995) found that the teachers had some difficulties to have their students take action on environmental issues though they had taken a course on teaching environmental issues. She suggested that the teachers be willing to include activities and concerns associated with environmental education in their classroom if they want their students to take action. As Cheng and So (2013), Cotton (2006), and Lee (2000) pointed out, this situation might be completely related to teachers' beliefs toward the environment and teaching strategies in environmental education.

Third, we associated the objectives at the 5th grade level with the justice-oriented citizenship category. This was not our expectation because usually educational programs were grounded on the personally responsible citizenship (Westheimer \& Kahn, 2004). In other words, the perspective of justice-oriented citizenship was least commonly pursued compared to participatory citizenship as Westheimer and Kahn (2004) reminded us. Furthermore, the whole curriculum did not include the participatory environmental citizenship aspects in terms of objectives. Yet, participation in the making process within the environmental context was essential to reshape the individual and society. It could help individuals to respond to social problems and structural critiques (Ellis \& Waterton, 2004; Schild, 2016).

Finally, the content presented in the textbook represented critical environmental literacy more. Interestingly, the content we analyzed in terms of environmental citizenship was more related to justice-oriented environmental citizenship. Therefore, the text had the potential to help students develop critical viewpoints about environmental issues from critical environmental literacy and justice-oriented citizenship aspects and take social action to make a change in their environment. In this sense, we agreed with Dimick (2015) on that helping students to generate personalities toward social and environmental justice was a specific challenge in environmental education.

\section{References}

Acuna, V. (2015). Environmental citizenship in Chilean school textbooks: A case study on environmental citizenship education in Chilean basic-education textbooks of 2012. [Unpublished master's thesis]. The University of British Columbia.

Aikenhead, G.S. (1992). The integration of STS into science education. Theory into Practice, 31, 27-35. https://doi. org/10.1080/00405849209543521

Barraza, L. (2001). Environmental education in Mexican schools: The primary level. The Journal of Environmental Education, 32(3), 31-36. https://doi. org/10.1080/00958960109599143

Berkowitz, A. J., Ford, M. A., \& Brewer, C. A. (2005). A framework for integrating ecological literacy, civics literacy, and environmental citizenship in environmental education. In E. A. Johnson \& M. J. Mapping (Eds.), Environmental education and advocacy: Changing perspectives of ecology and education (pp. 227-266). Cambridge University Press.

Carvalho, G. S., Tracana, R. B., Skujiene, G. \& Turcinaviciene, J. (2011). Trends in environmental education images of textbooks from western and eastern European countries and non-European countries. International Journal of Science Education, 33(18), 2587-2610. https://doi.org/10.1080/09500693.2011.556831

Cermak, M. J. (2012). Hip-hop, socialjustice, and environmental education: Toward a critical ecological literacy. Journal of Environmental Education, 43(3), 192-203. https://doi. org/10.1080/00958964.2011.633579

Chawla, L., \& Cushing, D. F. (2007). Education for strategic environmental behavior. Environmental Education Research, 13, 437-452. https://doi. org/10.1080/13504620701581539

Cheng, I. N. Y. \& So, W. W. M. (2015). Teachers' environmental literacy and teaching stories of three Hong Kong primary school teachers. International Research in Geographical and Environmental Education, 24(1), 5879. https://doi.org/10.1080/10382046.2014.967111

Cotton, D. R. E. (2006). Implementing curriculum guidance on environmental education: The importance of teachers' beliefs. Journal of Curriculum Studies, 38(1), 67-83. https://doi.org/10.1080/00220270500038644 
Craig, C. A., \& Allen, M. W. (2015). The impact of curriculumbased learning on environmental literacy and energy consumption with implications for policy. Utilities Policy, 35, 41-49. https://doi.org/10.1016/j. jup.2015.06.011

Creswell, J. W. (2007). Qualitative inquiry and research design: Choosing among five approaches. Sage Publications.

Creswell, J. W. (2014). Research design qualitative, quantitative and mixed methods approaches (4th ed.). Sage Publications.

Dimick, A.S. (2015). Supporting youth to develop environmental citizenship within/against a neoliberal context. Environmental Education Research, 21(3), 390402. https://doi.org/10.1080/13504622.2014.994164

Dobson, A. (2007). Environmental citizenship: Towards sustainable development. Sustainable Development, 15(5), 276-285. https://doi.org/10.1002/sd.344

Ellis, R., \& Waterton, C. (2004). Environmental citizenship in the making: The participation of volunteer naturalists in UK biological recording and biodiversity policy. Science and Public Policy, 31, 95-105. https://doi.org/10.3152/147154304781780055

Erdogan, M., Kostova, Z., \& Marcinkowski, T. (2009). Components of environmental literacy in the elementary education curriculum in Bulgaria and Turkey. Eurasia Journal of Mathematics, Science \& Technology Education, 5(1), 15-26.

https://doi.org/10.12973/ejmste/75253

European Network for Environmental Citizenship (2018a). Defining "Environmental Citizenship". http://eneccost.eu/our-approach/enec-environmentalcitizenship/

Gillian, K., \& Niranjan, C. (2019). Developing teachers' environmental literacy through inquiry-based practices. Eurasia Journal of Mathematics, Science and Technology Education, 15(6), 1-9. https://doi. org/10.29333/ejmste/103065

Goldman, D., Hansmann, R., Činčera, R., Radović, V., Telešienè, A., Balžekienè, A., Vávra, J. (2020). Education for environmental citizenship and responsible environmental behaviour. In A. C. Hadjichambis, P. Reis, D. Paraskeva-Hadjichambi, J. Cinčera, J. Boeve-de Pauw, N. Gericke, M. C. Knippels (Eds.), Conceptualizing environmental citizenship for 21st century education (pp. 115-138). Springer Open.

Green, C., Medina-Jerez, W., \& Bryant, C. (2016). Cultivating environmental citizenship in teacher education. Teaching Education, 27(2), 117-135. https://doi.org/10.1080/10476210.2015.1043121

Hart, P. (2002). The environment in the science curriculum: The politics of change in the Pan-Canadian science curriculum development process. International Journal of Science Education, 24(11), 1239-1254. https:// doi.org/10.1080/09500690210137728
Hollweg, K. S., Taylor, J. R., Bybee, R. W., Marcinkowski, T. J., McBeth, W. C., \& Zoido, P. (2011). Developing a framework for assessing environmental literacy. North American Association for Environmental Education. http://www.naaee.net.

Horwitz, W. A. (1996). Developmental origins of environmental ethics: The life experiences of activists. Ethics and Behavior, 6(1), 29-54. https://doi.org/10.1207/ s15327019ebo601_3

Innes, S., Skeaff, S., Shephard, K., Furnari, M., Harraway, J., Jowett, T., Lovelock, B., \& Strack, M. (2018). Greening the curriculum to foster environmental literacy in tertiary students studying human nutrition. Journal of Hunger and Environmental Nutrition, 13(2), 192-204. https://doi.org/10.1080/19320248.2016.1255693

The Islamic Foundation for Ecology and Environmental Sciences (2015). Islamic Declaration on Global Climate Change. http://www.ifees.org.uk/wpcontent/ uploads/2016/10/climate_declarationmMWB.pdf

Kim, K-O. (2003). An inventory for assessing environmental education curricula. The Journal of Environmental Education, 34(2), 12-18. https://doi.org/10.1080/00958960309603495

Klakayan, J., \& Singseewo, A. (2016). The development of a curriculum for renewable energy: A case study of charcoal briquettes from agricultural residues for environmental literacy of secondary school students at Samaki Whittaya municipality school. Journal of Education and Learning, 5(2), 121-128. http://dx.doi.org/10.5539/jel.v5n2p121

Krippendorff, K. (2018). Content Analysis: An Introduction to its methodology (4th ed.). Sage Publications.

Lee, J. Chi-Kin. (2000). Teacher receptivity to curriculum change in the implementation stage: The case of environmental education in Hong Kong. Journal of Curriculum Studies, 32(1), 95-115. https://doi. org/10.1080/002202700182871

McBeth, W., \& Volk, T. L. (2009). The national environmental literacy project: A baseline study of middle-grade students in the United States. The Journal of Environmental Education, 41(1), 55-67. https://doi. org/10.1080/00958960903210031

Ministry of Education. (2005). Middle school science curriculum. MoNE.

Ministry of Education. (2013). Primary and middle school science curriculum. MoNE.

Ministry of Environment and Forestry. (2004). Environmental atlas of Turkey. http://ahmetsaltik.net/arsiv/2012/06/ Turkiye_Cevre_Atlasi_Cevre_Bakanligi.pdf

Ministry of Environment and Urbanization. (2011). State of the environment report for the Republic of Turkey. http:// wwww.csb.gov.tr/turkce/dosya/ced/TCDR_2011.pdf

Ministry of Environment and Urbanization (2011). The Republic of Turkey: Climate change action plan (2011-2023). http://www.dsi.gov.tr/docs/iklimdegisikligi/\%C4\%B1depeng.pdf?sfvrsn=2 
NAEE (2015). The environmental curriculum: Opportunities for environmental education across the national curriculum for England. http://naee.org.uk/ curriculum-resources/

National Research Council. (1996). National science education standards. National Academies Press. https://doi. org/10.17226/4962.

National Research Council. (2013). Next-generation science standards for states, by states. The NationalAcademies Press. https://doi.org/10.17226/18290.

National Science Teachers Association (NSTA). (2003). NSTA position statement: Environmental education. NSTA. http://www.nsta.org/about/positions/ environmental.aspx

Negev, M., Sagy, G., Garb, Y., Salzberg, A., \& Tal, A. (2008). Evaluating the environmental literacy of Israeli elementary and high school students. The Journal of Environmental Education, 39(2), 3-20. https://doi. org/10.3200/JOEE.39.2.3-20

Organization for Economic and Co-operation and Development [OECD] (2016). PISA 2015 assessment and analytical framework: Science, reading, mathematics, and financial literacy. PISA, OECD Publishing. http://www.oecd-ilibrary.org/ education/pisa-2015-assessment-and-analyticalframework_9789264255425-en

Ross, H. (2007). The environment in the curriculum: representation and development in the Scottish physical and social sciences. Journal of Curriculum Studies, 39(6), 659-677. https://doi. org/10.1080/00220270701570304

Roth, C. E. (1992). Environmental literacy: Its roots, evolution, and directions in the 1990s. ERIC Clearinghouse for Science, Mathematics, and Environmental Education.

Schild, R. (2016). Environmental citizenship: What can political theory contribute to environmental education practice? The Journal of Environmental Education, 47(1), 19-34. https://doi.org/10.1080/00958964.2015. 1092417

Short, P. C. (2010). Responsible environmental action: Its role and status in environmental education and environmental quality. The Journal of Environmental Education, 41(1), 7-21. https://doi. org/10.1080/00958960903206781

Salmon, J. (2000). Are we building environmental literacy? The Journal of Environmental Education, 31(4), 4-10. https://doi.org/10.1080/00958960009598645

Smederevac-Lalic, M., Finger, D., Kovách, I., Lenhardt, M., Petrovic, J., Djikanovic, V., Conti, D., \& Boeve-de Pauw, J. (2020). Knowledge and environmental citizenship. In A.C. Hadjichambis, P. Reis, D. Paraskeva-Hadjichambi, J. Činčera, J. Boeve-de Pauw, N. Gericke, M.C. Knippels (Eds.), Conceptualizing environmental citizenship for 21st century education (pp. 69-82). Springer Open.

Srbinovski, M. (2013). Environmental education in Macedonian schools: A comparative analysis of textbooks. Applied Environmental Education \& Communication, 12(3), 163172. https://doi.org/10.1080/1533015X.2013.838867
Srbinovski, M., Erdogan, M., \& Ismaili, M. (2010). Environmental literacy in the science education curriculum in Macedonia and Turkey. Procedia Social and Behavioral Sciences, 2, 4528-4532. https://doi.org/10.1016/j. sbspro.2010.03.725

Sontay, G., Gokdere, M., \& Usta, E. (2015). A comparative investigation of sub-components of environmental literacy at the secondary school level. Journal of Turkish Science Education, 12(1), 19-28. https://doi. org/10.12973/tused.10130a

Stables, A. (1998). Environmental literacy: Functional, cultural, and critical. The case of the SCAA guidelines. Environmental Education, 4, 155-164. https://doi.org/10.1080/1350462980040203

Stevenson, R.B. (2007). Schooling and environmental education: Contradictions in purpose and practice. Environmental Education Research, 13(2), 139-153. https://doi.org/10.1080/13504620701295726

Turan, E., \& Bayrakdar, E. (2020). Türkiye'nin su yönetim politikaları: Ulusal güvenlik açısından bir değerlendirme. Uluslararası Politik Araştırmalar Dergisi, 6(2), 1-19. https://doi.org/10.25272 /j.2149-8539.2020.6.2.01

The Scientific and Technological Research Council of Turkey. (2004). National science and technology policies: 2003-2023-strategy document.

https://www.tubitak.gov.tr/tubitak_content_files// vizyon2023/Vizyon2023_Stratej i_Belgesi.pdf

UNESCO (1989). Environmental literacy for all. Connect, 14(2), 1.

United Nations Educational, Scientific, and Cultural Organization (UNESCO)/ United Nations Environment Programme (UNEP). (1976). The Belgrade Charter. Connect: UNESCO/UNEP Environmental Education Newsletter, 1(1), 1-2.

United Nations Educational, Scientific, and Cultural Organization (UNESCO)/ United Nations Environment Programme (UNEP). (1978). The Tbilisi declaration. Connect, 3(1), 1-8.

United Nations Framework Conventions on Climate Change (2016). The Paris agreement. https://unfccc.int/ resource/docs/2015/cop21/eng/10a01.pdf

Venville, G., Rennie, L. J., \& Wallace, J. (2009). Disciplinary versus integrated curriculum: The challenge for school science. The New Critic, 10, 1-9.

Walker, K.E. (1995). The teaching and learning of environmental education in NSW primary schools: A case study. Australian Journal of Environmental Education, 11, 121129. https://doi.org/10.1017/S0814062600003013

Weber, M. (1978). The nature of social action. In W. Runciman (Ed.) \& E. Matthews (Trans.), Max Weber: Selections in translation (pp. 7-32). Cambridge University Press. https://doi.org/10.1017/CBO9780511810831.005

Westheimer, J., \& Kahn, J. (2004). What kind of citizen? The politics of educating for democracy. American Educational Research Journal, 24(20), 237-269. https://doi.org/10.3102/00028312041002237 
Yucel-Ozata, E., \& Ozkan, M. (2014). A comparative study of the subjects on the ecosystem, biological diversity, and environmental problems in the Turkish science curriculum with the international curricula. Journal of Turkish Science Education, 11(4), 31-46. https://doi. org/10.12973/tused.10125a

\section{Appendices}

\section{Appendix A: Potential objectives associated with environmental literacy}

\section{A. Functional Environmental Literacy}

\section{Criteria}

F1) Providing of saying or remembering what is meant by a concept regarding environment.

F2) Provides the recognition of a concept related to the environment among the similar concepts.

F3) Providing of distinguishing the differences of the concepts related to the environment.

F4) Provides the knowledge about which part of the environment is formed by a concept of environment.

F5) Provides the ability to make an informed guess about what something half-known is likely to be by using observation from contextual cues.

\section{B. Cultural Environmental Literacy}

\section{Criteria}

C1) Provides the ability to understand the significance that society attaches to the natural images in terms of culture (national parks, a specific treetype, Kangal dog, etc.)

C2) Provides the understanding that the environment is formed not merely by climate, glaciation and topography, but formed by shaping and enclosing the landscape that people owned for many centuries.

C3) Providing the knowledge of why the natural things are there when the causes are clearly not simply geological or climatic with no apparent human intervention.

C4) Providing the ability to accept the dominant value system/ cultural heritage regarding the culture that is in the environment.

C5) Provides the ability to acknowledge the metaphorical/ symbolic meanings of natural things they possess in that culture (As an English, knowing what is implied by the term heart of oak) even though there is not a scientific basis.

c6) Provides the ability to be aware of and conscious about the norms and values regarding the environment in the natural culture.

C7) To provide an understanding of the norms and values of the national culture in order to influence on the environmental change.

\section{Objectives}

F.5.1.5.1. Explains the destructive natural disasters caused by the natural processes.

F.5.6.2.1. Explains the importance of interaction between humans and environment.

The negative effects of environmental pollution on people's health are mentioned.

\section{Objectives}




\section{(Appendices Cont.)}

\section{Critical Environmental Literacy}

\section{Criteria}

Cr1) Provides the understanding of the factors that cause environmental change / problems.

Cr2) Provides forming a view on how to further oppose the environmental problems in a way that can be later traslated to action.

Cr3) Provides questioning of what a place or an environmental problem means for itself.

Cr4) Provides questioning of what a place or an environmental problem means for others.

Cr5) Provides questioning what might be the consequences of continuing the existing situation regarding a space or environmental problem.

Cr6) Provides questioning whether it should be acted differently for the solution of the problem.

Cr7) Provides questioning how it should be acted for the solution of the problem.

Cr8) Provides questioning of whether the existed value system is ready for change as a result of what is now known about the solution of the problem.

Crg) Provides questioning of how the existed value system should be translated into effective action.

\section{Objectives}

F.5.6.1.2. Discusses the factors that threatens biodiversity based on research data.

F.5.1.5.2. Expresses the ways of protection from the destructive natural disasters.

F.5.6.2.2. Provides suggestions for resolving an environmental problem in the immediate surrounding or in our country.

F.5.6.1.1. Questions the importance of biodiversity for natural life Gives examples to plants and animals that are endangered or facing danger of extinction in our country and in the world.

F.5.6.2.3. Makes inferences about the environmental problems that may arise in the future as a result of human activities.

F.5.6.2.4. Discusses the examples of cons and pros of the relationship between human and environment

\section{Appendix B: Potential objectives associated with environmental citizenship}

\section{A. Personally responsible citizen}

\section{Criteria}

P1- Demonstrates individual responsibility towards the environment in the community.

P2- Obeys the social rules and laws concerning the environment

P3- Attaches importance to recycling

P4- Be sensitive to environmental problems.

P5- Looks optimistically about and participates in environmental organizations.

\section{B. Participatory ciziten}

\section{Criteria}

Pa1- As an individual, he is part of an environmentally sensitive organization and is an active member of it.

Pa2- Participates in organizational work to develop and maintain sensitivity towards the environment.

Pa3- Attaches importance to the order and cleanness of the environment and encourages other people.

Pa4- Knows the institutions and organizations involved in the protection of the natural environment and knows the strategies necessary for exhibiting collective tasks.

\section{Objectives}

\section{Objectives}




\section{(Appendices Cont.)}

Pa5- Helps to do organizational work to protect the natural environment.

Pa6- Takes leadership and actively takes part in the protection of the natural environment.

\section{Justice-oriented citizen}

\section{Criteria}

J1- Critically assesses the problems or issues related to the environment and evaluates in terms of social, cultural, economic and political aspects.

J2- Considers the concept of justice to solve problems with a critical point of view.

J3- Takes leadership of change in order to avoid insensitivity to the environment with a democratic point of view.

J4- Analyzes the insensitivity and behaviors of people and society to solve environmental problems.

J5- Monitors and questions environmental issues for environmental justice, and tries to change the built-in system.

\section{Objectives}

F.5.6.1.1. Questions the importance of biodiversity for natural life. Gives examples to plants and animals that are endangered or facing danger of extinction in our country and in the world.

F.5.6.1.2. Discusses the factors that threatens biodiversity based on research data.

F.5.6.2.3. Makes inferences about the environmental problems that may arise in the future as a result of human activities.

F.5.6.2.4. Discusses the benefits and harmful situations in humanenvironment interaction on examples

F.5.6.2.2. Provides suggestions for resolving an environmental problem in the immediate surrounding or in our country. 